\title{
Farm level factors associated with feather pecking in organic laying hens
}

\author{
M.W.P. Bestman*, J.P. Wagenaar \\ Louis Bolk Institute, Hoofdstraat 24, 3972 LA Driebergen, The Netherlands
}

\begin{abstract}
Farm-level factors that could be associated with feather pecking of layers kept in organic farming systems were monitored in 63 flocks from 26 farms located in different areas of The Netherlands. Data on housing and management practices were collected and plumage damage as a measure of feather pecking was scored at 50 weeks of age or older. No or little plumage damage was found in 18 (29\%) flocks, moderate damage in 12 (19\%) flocks and severe damage in 33 (52\%) flocks. A high percentage of hens in the flock using the outdoor run, a young age at purchase and an increasing number of cockerels present in the flock were found to significantly decrease feather pecking damage at 50 weeks or older. Factors associated with increased usage of the outdoor run were smaller flock size, a young age at purchase, an increasing number of cockerels present in the flock and a higher percentage of cover in the run. Based on the results organic farmers are likely to benefit from rearing their own layers. They should keep cockerels with their layers. Other practices resulting in low feather pecking damage are stimulating the use of the outdoor run by making it attractive with vegetative or artificial cover or keeping the flock size at around 500 birds.
\end{abstract}

(C) 2002 Elsevier Science B.V. All rights reserved.

Keywords: Feather pecking; Organic poultry; Outdoor run; Cockerels; Flock size; Rearing

\section{Introduction}

\subsection{Feather pecking}

Feather pecking can be a serious problem in poultry husbandry and is seen not only in cages, but also in alternative housing systems (Appleby and Hughes, 1991). In the last 2 decades, a lot of

\footnotetext{
*Corresponding author. Tel.: +31-343-523-860; fax: +31-343515-611.

E-mail address: m.bestman@louisblok.nl (M.W.P. Bestman).
}

research has been conducted to find the mechanism of development of this behaviour. One hypothesis is that feather pecking is redirected ground pecking behaviour and, more precisely, that it might be related to foraging behaviour (Blokhuis and Arkes, 1984). Another hypothesis is that feather pecking originates from pecking behaviour, performed during dust bathing (Vestergaard et al., 1993). Recently, studies have also been published in which several factors on large numbers of alternative commercial farms were involved (Gunnarsson et al., 1999; Huber-Eicher and Audigé, 1999; Green et al., 2000). In these studies risk factors for feather pecking were 
identified such as stocking density $>10$ birds per $\mathrm{m}^{2}$ during rearing, having no access to elevated perches during rearing (Huber-Eicher and Audigé, 1999), less than $50 \%$ of the birds from a flock using the outdoor run, diet being changed three or more times during lay, inspections done by one person, no loose litter being left by the end of lay, hen house temperature being less than $20^{\circ} \mathrm{C}$, lights turned up when the flock was inspected and bell drinkers were used (Green et al., 2000). However, Gunnarsson et al. (1999) did not find significant relations between housing factors and feather pecking, probably because of their low sample size.

Feather pecking is defined as the pecking at and pulling out of feathers of another chicken. Often these feathers are eaten as well. Feather pecking is an indicator of reduced welfare in both victim and performer. Pulling out feathers is painful and chickens with feather damage are more susceptible to further feather pecking and injurious pecking (McAdie and Keeling, 2000). A Swiss study (ElLethey et al., 2000) showed that the performance of feather pecking is associated with stress because physiological indicators for stress were observed in the same experimental groups as feather pecking. Apart from reduced animal welfare, feather pecking in commercial farms is an economic problem, even if it does not result in increased mortality or lower production: chickens with feather damage need more feed in order to maintain their body temperature, which can rise up to $27 \%$ (Tauson and Svensson, 1980).

As mentioned previously, feather pecking is also seen in alternative housing systems. None of the studies that focused on commercial farms previously mentioned, looked at organic poultry farms. However, these have the strictest housing regulations (e.g. relative low density, limited group size, access to litter and to an outdoor run). They thus seem to be more welfare friendly, assuming that feather pecking is related to stress, thus less susceptible for feather pecking than other alternative systems. However, feather pecking still is a major concern on many organic farms [Kjaer (1999) cited from Kjaer and Sørensen (2002); Bestman (2000)]. In this article, the results of a study that has been carried out in organic Dutch poultry farms to find farm-level factors that can be associated with feather pecking, are presented.

\subsection{Organic poultry husbandry in the Netherlands}

In the philosophy of organic farming (Alrøe et al., 2001; Lund and Röcklinsberg, 2001) farm animals should be kept in such a manner that they can express their natural behaviour. Moreover, their species-specific characteristic should be respected. The latter means no mutilations such as beak trimming. Although not mentioned explicitly, feather pecking as a kind of deviant behaviour in organic systems is regarded as undesirable behaviour. Alrøe et al. (2001) stated that when welfare problems occur, solutions should primarily be sought at the systemic level (instead of adapting the animals to the system).

According to Council Regulation (EC) 1804/ 1999, some of the most important features for organic poultry keeping are six hens $/ \mathrm{m}^{2}$ in the hen house, $4 \mathrm{~m}^{2}$ per hen vegetated outdoor area, $18 \mathrm{~cm}$ perch length per hen, at least $33 \%$ of the floor area should be covered with litter, with plenty of daylight and natural ventilation available. Day length may be increased to a maximum of $16 \mathrm{~h}$, maximum flock size is 3000 hens. Because these regulations have been in force since August 2000, and some of the data from the study presented here, are from before that date, the database of our study also contains some larger flocks. Diets should be of organic origin for at least $80 \%$ and roughage should be provided daily. Beak trimming is prohibited. In the Netherlands 90 organic farms keep poultry and about one third of them has more than 1000 hens. In total, some 120 000-140 000 organic laying hens are kept. Among them are the biodynamic farmers who work according stricter rules, such as a maximum of five hens per $\mathrm{m}^{2}$ and one cock for every thirty hens.

\section{Materials and methods}

\subsection{Data collection}

From 1999 to 2001, a total of 63 flocks of organic laying hens from 26 farms were monitored. Names 
and addresses of the farmers came from the address list of the Dutch control agency for organic agriculture, Skal (Zwolle, The Netherlands) which contains 90 poultry farms. A first selection was made based on farm size. Only farms with at least 100 layers were considered. Out of 35 farms 30 agreed to participate in the study. All these farms were visited. During the visit farmers were interviewed about their motivation to convert to organic poultry keeping and their experience with organic as well as conventional poultry keeping so far. Daily management, housing and behaviour of the layers (using the outdoor run, feather pecking) were also discussed. The percentage of the total outdoor area available to the layers covered with vegetative or artificial cover of at least $1 \mathrm{~m}$ high was also estimated by the interviewer.

Flocks on participating farms were scored for plumage damage when they passed the age of 50 weeks. This meant that in many cases the interviewer had to revisit the farm. It was assumed that all plumage damage was caused by feather pecking. The body of a layer was divided into nine areas that were scored on a scale from 1 (no damage) to 9 [blood or (old) wound visible]. Plumage damage score (PDS) was performed on a sample of 40 birds. In order to prevent scoring the same bird twice in smaller flocks a sample size of 20 was used. Birds were randomly scored at a transect, both inside the hen house and in the outdoor area. In order not to disturb the animals and to prevent selecting relatively tame birds, birds were not handled, but scored within a distance of 2 $\mathrm{m}$ from the observer. Based on the sample, a mean PDS was calculated for each flock. Flocks were only included in the database if they had been stable groups during the whole production cycle, i.e. when no replacement birds had been introduced. Flocks consisting of different hybrids or different age groups were excluded from analysis. Four flocks on four farms were excluded for these reasons.

\subsection{Statistical analysis}

Statistical analysis was performed with GenStat (2001). Response variables were checked for normal distribution. The distribution of available data on PDS showed no major deviations. The distribution of data on the percentage of hens using the outdoor run
(Run\%) was slightly skewed. Log (base e) transformation improved the distribution of Run\%. Due to missing information not all flocks could be included in the models presented hereafter. Models were established for PDS and LogRun\% using multiple linear regression. The general model was as follows:

$$
\begin{aligned}
\operatorname{PDS}_{\mathrm{i}} \text { or LNRun\% } \%_{i}= & \alpha+\beta_{1} X_{1}+\beta_{2} X_{2}+\ldots \\
& +\beta_{k} X_{k}+e_{i}
\end{aligned}
$$

where $\alpha$ is the intercept, $\beta_{k}$ is the regression coefficient of management practice $X_{k}$ and $e_{i}$ is the residual random error.

The selection of the model involved two steps. In the first step SELECT (Biometris, 2001) was used to select candidate regression models. In this study adjusted $R^{2}$ and Mallows $\mathrm{Cp}$ were used as criteria to evaluate candidate regression models. In the case of PDS 12 terms were included in the SELECT procedure and in the case of LNRun\%, 8. Terms were preselected on their biological relevance for each of the models.

In the second step the correlation between terms found in the best regression model using SELECT were studied using Summary Statistics (GenStat, 2001). In case no irregularities were encountered terms were fitted using the FIT procedure (GenStat, 2001). Only terms significant at a $P$ value $<0.05$ in the $F$ test were retained in the final models. Where relevant, predicted values were compared using the RPAIR procedure (Biometris, 2001).

\section{Results}

All general information about the farms and flocks is presented in Table 1. Because the information was not complete for every flock, the number of flocks with information about a certain factor, varies.

\subsection{Factors associated with feather pecking}

For plumage damage score (PDS) two possible models were selected. The first model only included the percentage of hens that went outside under optimum conditions (Run\%; $P<0.001$ ):

$$
\text { PDS }=4.98-0.03 \cdot \operatorname{Run} \%\left(R_{\text {adj }}^{2}: 38 \%, \text { Cp: } 1.92\right)
$$


Table 1

General information about the farms and flocks

\begin{tabular}{|c|c|c|c|}
\hline Level & Factor & Feature & Frequency \\
\hline \multirow[t]{3}{*}{ Farm } & $\begin{array}{l}\text { Experience of } \\
\text { the farmer }\end{array}$ & $\begin{array}{l}\leq 5 \text { years } \\
6-10 \text { years } \\
\geqslant 11 \text { years }\end{array}$ & $\begin{array}{l}19 / 26(73 \%) \\
5 / 26(19 \%) \\
2 / 26(8 \%)\end{array}$ \\
\hline & Farming system & $\begin{array}{l}\text { Organic } \\
\text { Biodynamic }\end{array}$ & $\begin{array}{l}20 / 26(77 \%) \\
6 / 26(23 \%)\end{array}$ \\
\hline & Hens per farm & $\begin{array}{l}\leq 1000 \\
1001-2000 \\
\geqslant 2001\end{array}$ & $\begin{array}{l}8 / 26(31 \%) \\
7 / 26(27 \%) \\
11 / 26(42 \%)\end{array}$ \\
\hline \multirow[t]{13}{*}{ Flock } & Hybrids & $\begin{array}{l}\text { Bovans Nera } \\
\text { Bovans Goldline } \\
\text { Isabrown } \\
\text { Other }\end{array}$ & $\begin{array}{l}20 / 62(32 \%) \\
20 / 62(32 \%) \\
11 / 62(18 \%) \\
11 / 62(18 \%)\end{array}$ \\
\hline & Age at purchase & $\begin{array}{l}\text { 1-Day chick } \\
5-8 \text { weeks (switch from } \\
\text { warm to cold rearing) } \\
\text { 16-18 weeks (just } \\
\text { before onset of lay) } \\
\text { Other }\end{array}$ & $\begin{array}{l}4 / 62(6 \%) \\
15 / 62(24 \%) \\
37 / 62(60 \%) \\
6 / 62(10 \%)\end{array}$ \\
\hline & $\begin{array}{l}\text { Bird density } \\
\text { in stable }\end{array}$ & $\begin{array}{l}\text { Mean } 4.8 \text { birds } / \mathrm{m}^{2} \\
\quad(\text { range } 2.7-6)\end{array}$ & \\
\hline & Flock size & $\begin{array}{l}\leq 1000 \\
1001-2000 \\
\geqslant 2001\end{array}$ & $\begin{array}{l}25 / 63(40 \%) \\
13 / 63(21 \%) \\
25 / 63(40 \%)\end{array}$ \\
\hline & $\begin{array}{l}\text { Cockerels between } \\
\text { the hens }\end{array}$ & Yes & $16 / 59(27 \%)$ \\
\hline & & No & $43 / 59(73 \%)$ \\
\hline & Rearing season & $\begin{array}{l}\text { Spring } \\
\text { Summer } \\
\text { Autumn } \\
\text { Winter }\end{array}$ & $\begin{array}{l}18 / 63(29 \%) \\
15 / 63(24 \%) \\
12 / 63(19 \%) \\
18 / 63(29 \%)\end{array}$ \\
\hline & $\begin{array}{r}\text { Scattered grain } \\
(\mathrm{g} / \mathrm{hen} / \text { day })\end{array}$ & $\begin{array}{l}\leq 10 \\
11-20 \\
\geqslant 21\end{array}$ & $\begin{array}{l}27 / 54(50 \%) \\
16 / 54(30 \%) \\
11 / 54(20 \%)\end{array}$ \\
\hline & $\begin{array}{l}\text { Access to outdoor } \\
\text { run daily? }\end{array}$ & $\begin{array}{l}\text { Yes } \\
\mathrm{No}^{\mathrm{a}}\end{array}$ & $\begin{array}{l}33 / 62(53 \%) \\
29 / 62(47 \%)\end{array}$ \\
\hline & $\begin{array}{l}\text { Time of opening } \\
\text { of pop-holes }\end{array}$ & $\begin{aligned} \leq & 10 \text { a.m. (before or } \\
& \text { during lay of eggs) } \\
\geqslant & 11 \text { a.m. (after } \\
& \text { eggs being laid) }\end{aligned}$ & $\begin{array}{l}31 / 57(54 \%) \\
26 / 57(46 \%)\end{array}$ \\
\hline & $\begin{array}{l}\text { Cover in outdoor } \\
\text { run }^{\mathrm{b}}\end{array}$ & $\begin{array}{l}0-25 \% \\
26-50 \% \\
51-75 \% \\
76-100 \%\end{array}$ & $\begin{array}{l}45 / 59(76 \%) \\
5 / 59(8 \%) \\
6 / 59(10 \%) \\
3 / 59(3 \%)\end{array}$ \\
\hline & $\begin{array}{l}\text { Percentage of hens outside } \\
\text { under optimum } \\
\text { conditions (dry weather, } \\
\text { end of the day) }\end{array}$ & $\begin{array}{l}0-25 \% \\
26-50 \% \\
51-75 \% \\
76-100 \%)\end{array}$ & $\begin{array}{l}11 / 56(20 \%) \\
21 / 56(38 \%) \\
4 / 56(7 \%) \\
20 / 56(38 \%)\end{array}$ \\
\hline & $\begin{array}{l}\text { Plumage damage score } \\
\text { at } \geqslant 50 \text { weeks of age }\end{array}$ & $\begin{array}{l}\text { Little or no damage (PDS } \leq 2) \\
\text { Moderate damage (PDS 2.1-3) } \\
\text { Severe damage (PDS }>3 \text { ) }\end{array}$ & $\begin{array}{l}18 / 63(29 \%) \\
12 / 63(19 \%) \\
33 / 63(52 \%)\end{array}$ \\
\hline
\end{tabular}

\footnotetext{
${ }^{a}$ Reasons for not opening the pop-holes were that after arrival on the laying farm the farmer wanted the hens first get used to laying in the nests, bad weather or wet outdoor run and an outbreak of foot and mouth disease in the area. This meant that these flocks did not have access to the outdoor run from several weeks to several months during lay.

${ }^{\mathrm{b}}$ Defined as vegetation or artificial structures of at least $1 \mathrm{~m}$ high under which hens could walk. This cover varied from vegetation such as maize or willow trees (Salix) to camouflage nets.
} 
Based on this model it was calculated that severe feather pecking (PDS $\geqslant 3$ ) did not occur when twothirds $(66 \%)$ of the birds or more made use of the outdoor run.

The second model found was:

$$
\begin{array}{ll}
\mathrm{PDS}=2.87+0.14 \cdot \mathrm{AP}-39.9 \cdot \mathrm{CR}- & 0(\mathrm{SR} 1) \\
& 1.47(\mathrm{SR} 2) \\
& 0.90(\mathrm{SR} 3) \\
& 1.31(\mathrm{SR} 4) \\
\left(R_{\mathrm{adj}}^{2}: 46 \%, \mathrm{Cp}: 2.77\right) &
\end{array}
$$

Season of rearing (SR) was not significant $(P<$ 0.08 ), but could not be removed from the model. Significant contributions to the second model were made by Age at Purchase (AP; $P<0.001)$ and Cockerel Ratio (CR; $P<0.009)$.

However, the other factors-experience of the farmer, organic versus biodynamic, hybrid, bird density, time spent with animals, amount of grain scattered daily, rearing season and daily access to outdoor run-were not significant.

\subsection{Factors associated with the use of the outdoor run}

For the percentage of hens that use the outdoor run under optimum conditions (LNRun\%) the following model was found:

$$
\begin{gathered}
\text { LNRun\% }=4.46-0.00014 \cdot \mathrm{FS} 1-0.032 \cdot \mathrm{AP} \\
+6.82 \cdot \mathrm{CR}+0.0037 \cdot \mathrm{PRC} \\
\left(R_{\text {adj }}^{2}=77.0 ; \mathrm{Cp}=3.92\right)
\end{gathered}
$$

Flock size (FS; $P<0.001$ ), Age at Purchase (AP; $P<0.001$ ), Cockerel Ratio (Cockerels per hen: CR; $P<0.017)$ and Percentage of Run Coverage over 1 $\mathrm{m}$ high (PRC; $P<0.015)$ all contributed significantly. It seems the younger the birds arrive on the laying farm (i.e. the larger the part of the rearing done on laying farm) the more birds use the outdoor area and, the more birds in one flock, the smaller the use of the outdoor run. Finally it also seems that the larger the ratio between cocks and hens in a flock and the more cover is available in the outdoor run, the more birds used the outdoor run. However, the other factors-experience of the farmer, bird density, rearing season and daily access to outdoor run-were not significant.

\section{Discussion}

The younger the hens arrived on the laying farm, the lesser feather pecking was seen during lay. This can be caused by 'organic circumstances' at a younger age, such as access to the outdoor area, lower stocking density, smaller group size, perches, grain scattered and roughage fed daily, etc. Moreover, change of environment at a younger age might be less stressing for the birds. Other studies have found that lower stocking density during rearing results in less feather pecking (Huber-Eicher and Audigé, 1999), as well as the combination of lower stocking density and smaller group size (Nicol et al., 1999; Savory et al., 1999). High perches prevent feather damage at least during the laying period (Wechsler and Huber-Eicher, 1998). Grain scattered as a pecking incentive during rearing (Blokhuis and van der Haar, 1992) and feeding roughage (Steenfeldt et al., 2001) may also reduce feather pecking.

The relationship between the presence of cockerels with the hens and feather pecking is unclear. Cocks are known to reduce the number of aggressive interactions between hens (Craig and Bhagwat, 1974; Bshary and Lamprecht, 1994), but not feather pecking (Odén et al., 1999). Cockerels are also known to guide the hens to feed (Bshary and Lamprecht, 1994) and nests (Vestergaard, 1981, pp. 4-5). According to some of the farmers interviewed, cockerels are the first to go outside after opening the pop-holes and they defend hens against predators. It is possible that cockerels form a natural and appropriate enrichment of the environment of the hens. Other types of environmental enrichment such as foraging materials (Huber-Eicher, 1999), scattered grains (Blokhuis and van der Haar, 1992), high perches (Wechsler and Huber-Eicher, 1998) and use of the outdoor run (Green et al., 2000; our study) have been shown to reduce feather pecking.

A significant relationship between feather pecking and the percentage of birds using the outdoor run has already been demonstrated by Green et al. (2000). This relationship may be explained by the higher density, increased group size and a poorer rich environment when more hens stay inside. Higher density (in combination with larger groups) is associated with more feather pecking (Nicol et al., 1999; Savory et al., 1999; Huber-Eicher and Audigé, 
1999). According to some interviewed farmers, feather pecking (defined as visible damage) started after they kept their hens inside. However, Häne et al. (2000) did not find a relation between provision of access to free range and the plumage condition. Our results show that it is not the provision of range that affects feather pecking, but the use of it; all flocks in our study had an outdoor run available, but large differences existed in its use.

For different behavioural aspects, such as perching (Gunnarsson et al., 1999), location of egg laying (Fölsch, 1981, p. 81), dustbathing and pecking behaviour (Blokhuis and van der Haar, 1992; Johnsen et al., 1998) it has been demonstrated that early rearing conditions affect the behaviour in adult hens. It is possible that access to an outdoor area at young age also influences the use at a later age. In general rearing farms in the Netherlands are rather reserved in opening the pop-holes for laying hen growers, in particular in case of rain, wind or cold. In addition, when the pop-holes are being opened, there is not much stimulation to go outside: the number of popholes is small and there is hardly any cover in the outdoor run, which makes it rather unattractive. This means that at the end of rearing, many flocks have little or even no experience of an outdoor area, especially flocks reared in autumn and winter. It is probable that farmers that do their own rearing are more conscious of the importance of rearing conditions generally and are also the ones that provide access to an attractive outdoor run at younger age. This could not be demonstrated with our data. However, Kjaer and Sørensen (2002) did not find a relation between age at access to range and plumage condition at 35 weeks of age.

A significant relation between flock size and use of the outdoor run has already been demonstrated by Bubier and Bradshaw (1998). They found that in a flock of 500 hens $42 \%$ went outside, in flocks of 1450 hens, $10 \%$ and in a flock of 2500 hens, $5 \%$. Hirt et al. (2000) found that in flocks of 500 birds the average of the hens outside was $47 \%$ and in flocks of 3000 this was $32 \%$. Appleby and Hughes (1991) reported that in flocks of 40 hens $80 \%$ went outside, while in flocks of 1000 or more, only $10 \%$ went outside. Our study showed that no severe feather pecking was seen as soon as $66 \%$ of the birds used the outdoor run. This might mean that the optimum flock size is below 500. It is not clear whether in the studies mentioned above cover was available in the outdoor run.

Our study finds a significant relationship between cover in the outdoor run and the percentage of birds seen outside under optimum weather conditions. Cover is defined as vegetation or artificial structures of at least $1 \mathrm{~m}$ high under which hens could walk, such as maize, (low) pollard willows (Salix) or camouflage nets. If cover was provided, even in flocks up to 2000 hens, more than $75 \%$ of the hens could be seen outside. Without any cover, flock size should not exceed 500 hens and more research is needed to what extend cover can contribute to attract larger flocks to the outdoor area. Experienced farmers interviewed also mentioned that apart from cover, the age of first access was important as was opening the pop-holes daily instead of keeping hens inside for consecutive weeks or months. Appleby and Hughes (1991) mention an uneven distribution of the hens in the pasture, perhaps because of fear of predators. Most hens only frequent the area directly around the stable or in the vicinity of shelter. The risk of such an uneven distribution is parasitic contamination (Bray and Lancaster, 1992) as well as the accumulation of nitrogen and phosphate (Meierhans and Menzi, 1995; c.f. Häne et al., 2000) in highly frequented places. Häne et al. (2000) suggest paddock rotation and offering dispersed shadow facilities as a solution to this. Furthermore, in The Netherlands a health survey together with parasitic samples was conducted (Landman et al., unpublished results); it was found that in one of the older farms with large numbers of birds (1500-2000) using the same outdoor run for 15 years without paddock rotation, there was no parasitic accumulation. However, this farm ploughs the outdoor run every year and sows maize in order to create shelter for the hens. It may be that, apart from a well distributed use, cultivation also has a positive effect on the parasitic accumulation. In addition, the growing and harvesting of crops might have a positive effect on the contamination with phosphates and nitrogen.

No literature was found about the relationship between the presence of cockerels in a flock and the use of the outdoor run by the flock. Some experienced farmers reported that after the pop-holes were opened, the cockerels were the first to enter the 
outdoor run. They also reported that when outside, nearly all hens stay in the vicinity of a cockerel. Some farmers had observed that cockerels defended hens against birds of prey, foxes and dogs.

There are several practical implications for organic poultry husbandry. Firstly organic farmers should buy hens at the age of at most 6 weeks and rear them on the laying farm. The age of $6(5-8)$ weeks is a logical choice, because it is then that the hens are normally moved from the heated rearing to the cold rearing stable. The flocks should be a mixture of cocks and hens. The animals should be stimulated to use the outdoor area as much as possible by providing access at young age, by making the outdoor run attractive with well-distributed cover or keeping flocks of at most 500 hens. It may also be advisable to cultivate the land regularly by ploughing and growing crops that provide shelter and can be harvested.

\section{Conclusion}

Our study demonstrates that feather pecking in organic laying hens is associated significantly with several housing and management practices. Less feather pecking is seen if farmers do their own rearing, in mixed groups of hens and cockerels and if more birds from a flock use the outdoor area. Use of the outdoor area is associated significantly with age at purchase, flock size, cockerels and cover in the outdoor run. More hens of a flock use the outdoor run when reared on the laying farm, in smaller flocks, if cockerels being kept with the hens and the more cover is observed in the outdoor run.

\section{References}

Alrøe, H.F., Vaarst, M., Kristensen, E.S., 2001. Does organic farming face distinctive livestock welfare issues?-a conceptual analysis. J. Agric. Environm. Ethics 14, 275-292.

Appleby, M.C., Hughes, B.O., 1991. Welfare of laying hens in cages and alternative systems: environmental, physical and behavioural aspects. World Poultry Sci. J. 47, 109-128.

Bestman, M.W.P., 2000. The role of management and housing in the prevention of feather pecking in laying hens. In: Proceedings of the 4th NAHWOA Workshop, Clermont-Ferrand, 2124 October.
Biometris (2001). Manual Genstat procedure, Library Release 4.2. Blokhuis, H.J., Arkes, J.G., 1984. Some observations on the development of feather-pecking in poultry. Appl. Anim. Behaviour Sci. 12, 145-157.

Blokhuis, H.J., van der Haar, J.W., 1992. Effects of pecking incentives during rearing on feather pecking of laying hens. Br. Poultry Sci. 33, 17-24.

Bray, T.S., Lancaster, M.B., 1992. The parasitic status of land used by free range hens. Br. Poultry Sci. 33, 1119-1120.

Bshary, R., Lamprecht, J., 1994. Reduction of aggression among domestic hens (Gallus domesticus) in the presence of a dominant third party. Behaviour 128, 311-324.

Bubier, N.E., Bradshaw, R.H., 1998. Movement of flocks of laying hens in and out of the hen house in four free range systems. Br. Poultry Sci. 39, S5-S18.

Craig, J.V., Bhagwat, A.L., 1974. Agonistic and mating behavior of adult chickens modified by social and physical environments. Appl. Anim. Ethology 1, 57-65.

El-Lethey, A.V., Jungi, T.W., Wechsler, B., 2000. Stress and feather pecking in laying hens in relation to housing conditions. Br. Poultry Sci. 41, 22-28.

Fölsch, D.W., 1981. Das Verhalten von legehennen in unterschiedlichen Haltungssystemen unter Berücksichtigung der Aufzuchtmethoden. In: Fölsch, D.W., Vestergaard, K. (Eds.), The Behaviour of Fowl. the Normal Behaviour and the Effect of Different Housing Systems and Rearing Methods. Birkhäuser, Basel-Boston-Stuttgart, pp. 88-94.

GenStat, 2001. 5th Edition-Release 4.21. Lawes Agricultural Trust, Rothamsted Experimental Station.

Green, L.E., Lewis, K., Kimpton, A., Nicol, C.J., 2000. A cross sectional study of the prevalence of feather pecking in laying hens in alternative systems and its associations with management and disease. Vet. Rec. 147, 233-238.

Gunnarsson, S., Keeling, L.J., Svedberg, J., 1999. Effect of rearing factors on the prevalence of floor eggs, cloacal cannibalism and feather pecking in commercial flocks of loose housed laying hens. Br. Poultry Sci. 40, 12-18.

Häne, M., Huber-Eicher, B., Fröhlich, E., 2000. Survey of laying hen husbandry in Switzerland. World's Poultry Sci. J. 56, 21-31.

Hirt, H., Hördegen, P., Zeltner, E., 2000. Laying hen husbandry: group size and use of hen runs. In: Proceedings of 13th IFOAM Scientific Conference. Basel, Switzerland, p. 363.

Huber-Eicher, B., 1999. A survey of layer-type pullet rearing in Switzerland. World's Poultry Sci. J. 55, 83-91.

Huber-Eicher, B., Audigé, L., 1999. Analysis of risk factors for the occurrence of feather pecking in laying hen growers. $\mathrm{Br}$. Poultry Sci. 40, 599-604.

Johnsen, P.F., Vestergaard, K.S., Nørgaard-Nielsen, G., 1998. Influence of early rearing conditions on the development of feather pecking and cannibalism in domestic fowl. Appl. Anim. Behav. Sci. 60, 25-41.

Kjaer, J.B., Sørensen, P., 2002. Feather pecking and cannibalism in free-range poultry as affected by genotype, dietary level of methionine + cystine, light intensity during rearing and age at first access to the range area. Appl. Anim. Behav. Sci. 76, 21-39.

Lund, V., Röcklinsberg, H., 2001. Outlining a conception of 
animal welfare for organic farming systems. J. Agric. Environ. Ethics 14, 391-424.

McAdie, T.M., Keeling, L.J., 2000. Effect of manipulating feathers of laying hens on the incidence of feather pecking and cannibalism. Appl. Anim. Behav. Sci. 68, 215-229.

Meierhans, D., Menzi, H., 1995. Phosphatbelastung ist problematisch. Schweizerische Geflügelzeitung 8, 6-13.

Nicol, C.J., Gregory, N.G., Knowles, T.G., Parkman, I.D., Wilkins, L.J., 1999. Differential effects of increased stocking density, mediated by increased flock size, on feather pecking and aggression in laying hens. Appl. Anim. Behav. Sci. 65, $137-152$.

Odén, K., Vestergaard, K.S., Algers, B., 1999. Agonistic behaviour and feather pecking in single-sexed and mixed groups of laying hens. Appl. Anim. Behav. Sci. 62, 219-231.

Savory, C.J., Mann, J.S., Macleod, M.G., 1999. Incidence of pecking damage in growing bantams in relation to food form, group size, stocking density, dietary tryptophan concentrations and dietary protein source. Br. Poultry Sci. 40, 579-584.

Steenfeldt, S., Engberg, R.M., Kjaer, J.B., 2001. Feeding roughage to laying hens affects egg production, gastrointestinal parameters and mortality. In: Proceedings of the 13th European Symposium on Poultry Nutrition, Blankenberge, Belgium, pp. 238-239.

Tauson, R., Svensson, S.A., 1980. Influence of plumage condition on the hen's feed requirement. Swedish J. Agric. Res. 10, 35-39.

Vestergaard, K., 1981. Aspects of the normal behaviour of the fowl. In: Fölsch, D.W., Vestergaard, K. (Eds.), The Behaviour of Fowl. the Normal Behaviour and the Effect of Different Housing Systems and Rearing Methods. Birkhäuser, BaselBoston-Stuttgart, pp. 2-7.

Vestergaard, K.S., Kruijt, J.P., Hogan, J.A., 1993. Feather pecking and chronic fear in groups of red junglefowl: their relations to dustbathing, rearing environment and social status. Anim. Behav. 45, 1127-1140.

Wechsler, B., Huber-Eicher, B., 1998. The effect of foraging material and perch height on feather pecking and feather damage in laying hens. Appl. Anim. Behav. Sci. 58, 131-141. 